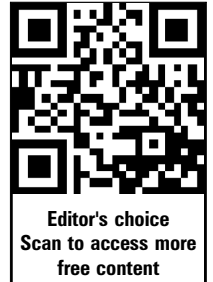

${ }^{1}$ Department of Occupational Medicine, Danish Ramazzini Centre, Aarhus University Hospital, Aarhus, Denmark ${ }^{2}$ Department of Occupational Medicine, Regional Hospital West Jutland-University Research Clinic, Herning, Denmark

\section{Correspondence to} Annett Dalbøge, Danish Ramazzini Centre, Department of Occupational Medicine, Aarhus University Hospital, Nørrebrogade 44, Building 2C, 8000 Aarhus N, Denmark; anetaner@rm.dk

Received 11 February 2014

Revised 2 July 2014

Accepted 16 July 2014

Published Online First

12 September 2014

\title{
Cumulative occupational shoulder exposures and surgery for subacromial impingement syndrome: a nationwide Danish cohort study
}

\author{
Annett Dalbøge, ${ }^{1}$ Poul Frost, ${ }^{1}$ Johan Hviid Andersen, ${ }^{2}$ Susanne Wulff Svendsen ${ }^{2}$
}

\begin{abstract}
Objectives The primary aim was to examine exposureresponse relationships between cumulative occupational shoulder exposures and surgery for subacromial impingement syndrome (SIS), and to compare sexspecific exposure-response relationships. The secondary aim was to examine the time window of relevant exposures.
\end{abstract}

Methods We conducted a nationwide register study of all persons born in Denmark (1933-1977), who had at least 5 years of full-time employment. In the follow-up period (2003-2008), we identified first-time events of surgery for SIS. Cumulative exposure estimates for a 10year exposure time window with a 1-year lag time were obtained by linking occupational codes with a job exposure matrix. The exposure estimates were expressed as, for example, arm-elevation-years in accordance with the pack-year concept of tobacco consumption. We used a multivariable logistic regression technique equivalent to discrete survival analysis.

Results The adjusted OR (OR adj $)$ increased to a maximum of 2.1 for arm-elevation-years, repetition-years and force-years, and to 1.5 for hand-arm-vibration-years. Sex-specific exposure-response relationships were similar for men and women, when assessed using a relative risk scale. The $\mathrm{OR}_{\mathrm{adj}}$ increased gradually with the number of years contributing to the cumulative exposure estimates. The excess fraction was $24 \%$.

Conclusions Cumulative occupational shoulder exposures carried an increase in risk of surgery for SIS with similar exposure-response curves for men and women. The risk of surgery for SIS increased gradually, when the period of exposure assessment was extended. In the general working population, a substantial fraction of all first-time operations for SIS could be related to occupational exposures.

\section{INTRODUCTION}

Subacromial impingement syndrome (SIS) can be used as a collective term for shoulder-area disorders including rotator cuff syndrome, bursitis and tendonitis of the rotator cuff muscles. ${ }^{1}$ In general working populations, the prevalence of SIS has been reported to be $2-8 \%,{ }^{2}{ }^{3}$ with a prevalence of $6-10 \%$ in occupational groups with high shoulder exposures. $^{4-7}$ An increasing incidence of surgery for SIS has been reported from the USA, ${ }^{8}$ the UK, ${ }^{9}$ Sweden ${ }^{10}$ and Denmark. ${ }^{11}$ In Denmark, the incidence of surgery for SIS increased from 3.3 to 14.8/ 10000 person-years in the period $1996-2008 .^{11}$

\section{What this paper adds}

- Exposure-response relationships between cumulative occupational shoulder exposures and surgery for subacromial impingement syndrome (SIS) have not been reported previously.

- Working with elevated arms, repetitive shoulder movements and forceful shoulder exertions carried a doubled risk of surgery for SIS. Use of hand-held vibrating tools carried an increase in risk by a factor of 1.5 .

- Sex-specific exposure-response relationships were similar for men and women, when assessed using a relative risk scale.

- Within a 10-year time window, the risk of surgery for SIS increased gradually with the number of years contributing to the cumulative exposure estimates.

- In the general working population, $24 \%$ of all first-time events of surgery for SIS could be related to occupational shoulder exposures.

Occupational biomechanical shoulder exposures in terms of upper arm elevation $>90^{\circ}$, forceful shoulder exertions and repetitive shoulder movements have been established as risk factors for clinically diagnosed SIS, ${ }^{2} 4{ }^{12-16}$ and exposure to hand-arm-vibrations (HAVs) may also be associated with an increased risk. ${ }^{2} 1217$ Whether work-related cases of clinically diagnosed SIS have characteristics that lead to surgery has only been addressed in one study, ${ }^{18}$ which suggested so. If a relationship between occupational shoulder exposures and surgery for SIS can be corroborated, this will provide a further incentive for prevention by reducing occupational shoulder exposures.

An increasing prevalence of clinically diagnosed SIS has been reported with increasing exposure duration $^{2} 419$ and intensity. ${ }^{12-15} 2021$ However, the majority of these studies were crosssectional $^{2} 4^{13-15} 19$ and therefore did not contribute with knowledge on the risk of new onsets. The few longitudinal studies that have focused on new onsets of clinically diagnosed SIS ${ }^{12}{ }^{20}$ (or SIS and other shoulder disorders ${ }^{21}$ ) in relation to occupational shoulder exposures have not applied cumulative exposure measures or addressed the time window of relevant exposures. Such knowledge 
would increase our understanding of potential injury mechanisms in terms of accumulation of biological effects, which may link exposure and outcome. ${ }^{22} 23$ Knowledge of the time window would also have implications for causal inference in individual cases, for example, in connection with workers' compensation claims, where discussions often concern the minimal duration of exposure, which may increase the risk. If the risk can be related to cumulative exposures, a logical next step will be to try to identify exposure intensities, which do not lead to an increased risk of SIS, even with prolonged exposure duration. This would be highly relevant to guide the planning of preventive actions.

The prevalence of clinically diagnosed SIS has been found to be largely equal among men and women in the general population $^{24}$ and in working populations. ${ }^{2} 121425$ Even so, it has been suggested that women may be more vulnerable to occupational shoulder exposures than men are ${ }^{26}$ and therefore less well protected by preventive guidelines, which disregard sex. ${ }^{27}$ Few studies have investigated sex differences in the occurrence of clinically diagnosed SIS. These studies have not identified differences in sex-specific relative risk estimates with respect to work with elevated arms $^{2}$ and repetitive work, ${ }^{6}$ whereas findings regarding forceful work have been inconsistent. ${ }^{2} 6$ Overall, existing knowledge regarding the vulnerability hypothesis is limited with respect to SIS, and sex-specific exposure-response relationships between cumulative occupational shoulder exposures and surgery for SIS have not been reported previously.

The primary aim of this study was to examine exposureresponse relationships between cumulative occupational shoulder exposures and surgery for SIS, and to compare the exposure-response relationships between men and women. The secondary aim was to examine the time window of relevant exposures.

\section{MATERIALS AND METHODS Study design}

We conducted a nationwide cohort study using data from Danish registers, that is, the Civil Registration System (CRS), ${ }^{28}$ the Supplementary Pension Fund Register, ${ }^{29}$ the Employment Classification Module $(E C M)^{30}$ and the National Patient Register (NPR), ${ }^{31}$ together with a job exposure matrix (JEM) based on experts' ratings of occupational shoulder exposures. ${ }^{18}$

The upcoming of the private healthcare sector in Denmark in the 2000s lead to a request for notification from private hospitals and clinics to NPR, which has been mandatory since 2003. Private hospitals offer services paid by taxes (either under the rules of 'free hospital choice' or as part of an agreement with an administrative region to minimise waiting lists for certain treatments) and services paid by insurance companies or private persons. The last-mentioned services may be less completely registered. $^{31}$

The Danish Data Protection Agency approved the study (j. no.: 2012-41-1187). In Denmark, register studies do not need to be approved by the Committee System on Biomedical Research Ethics.

\section{Population}

The cohort included all persons born in Denmark, excluding Greenland, between 1 January 1933 and 31 December 1977, who were alive and lived in Denmark on 31 December 2002 according to the CRS, and had at least 5 years of full-time employment between 1 January 1993 and 31 December 2007 according to the Supplementary Pension Fund Register. We excluded persons who underwent surgery for any shoulder disorder between 1 January 1996 (when the Danish version of the Nordic Medico-Statistical Committee Classification of Surgical Procedures came into force) and 31 December 2002 according to the NPR.

\section{Outcome}

The outcome was defined as first-time surgery for SIS registered with a relevant diagnostic code according to the International Classification of Diseases, 10th revision (M19 or M75.1-M75.9, without a subordinate diagnosis of M75.0, adhesive capsulitis of shoulder) and with a relevant surgery code according to the Danish Nordic Medico-Statistical Committee Classification (KNBA, KNBE, KNBF, KNBG, KNBH, KNBK, KNBL or KNBM).

\section{Exposure}

From the ECM, we obtained information on occupational codes according to the Danish version of the International Standard Classification of Occupations from 1988 (D-ISCO 88) for each job held since 1 January 1993 (the ECM does not hold occupational titles). For each year from 1993 and onwards, we allocated exposure measures to the cohort members by connecting their D-ISCO 88 codes with a JEM. The JEM was developed for a number of studies concerning SIS (including this study); its construction has been described previously. ${ }^{18}$ In brief, we excluded rare or obsolete occupational titles from the 2227 different occupational titles in D-ISCO 88 and divided the remaining 2042 titles into 172 groups of jobs with expected homogeneous shoulder exposures. Five specialists in occupational medicine independently rated each job group (in terms of a full working day of $7.5 \mathrm{~h}$ ) with respect to upper arm elevation $>90^{\circ}$ (duration), repetitive shoulder movements (duration and frequency; moderately and highly repetitive work defined as $\geq 4-15$ and $\geq 15$ movements per minute, respectively), forceful shoulder exertions (a five-point rating of intensity of exertion) ${ }^{32}$ and exposure to HAVs (duration and acceleration group, where low, moderate and high acceleration was defined as $<3, \geq 3-10$ and $>10 \mathrm{~m} / \mathrm{s}^{2}$ ). Duration was rated in half-hour intervals. For each job group, estimates of exposure durations and force were calculated as the mean of the experts' ratings; the exposure estimate, which occurred most frequently, was used as our estimate of the frequency of repetitive shoulder movements and of the HAV acceleration group. The experts were aware of the aim of the present study, but did not have information on the distribution of surgery for SIS across occupational titles.

Occupational titles with the same D-ISCO 88 code could occur in different job groups of the JEM, and to be able to apply the JEM using the available D-ISCO 88 codes, we had to reconfigure the JEM according to D-ISCO 88 codes. We obtained D-ISCO 88 code-specific estimates of exposure by averaging across the original JEM exposures represented by the occupational titles with the same D-ISCO 88 code.

The exposure estimates for each cohort member were adjusted according to year-by-year information on number of hours worked per week from the ECM. We adjusted the exposure estimates using the following factors: 1 ( $\geq 37 \mathrm{~h} /$ week), 0.75 ( $\geq 28$ to $<37 \mathrm{~h} /$ week), 0.5 ( $\geq 18.5$ to $<28 \mathrm{~h} /$ week), 0.25 ( $\geq 9$ to $<18.5 \mathrm{~h} /$ week $)$ and $0(0$ to $<9 \mathrm{~h} /$ week $)$. For years outside labour market and years of unemployment, we used exposure estimates of zero. In case of years of employment with missing D-ISCO 88 codes, the missing exposure estimates were replaced by the mean exposure for all the person years with information on D-ISCO 88 codes. Persons without any registered D-ISCO 88 codes were excluded as part of the group with less than 
5 years of full-time employment between 1 January 1993 and 31 December 2007.

For each cohort member, cumulative exposure estimates for a 10-year exposure time window with a 1-year lag time were calculated for each year in the follow-up period by summing up the exposure estimates in each 10-year time period. The cumulative exposure estimates were expressed in accordance with the pack-year concept of tobacco consumption. ${ }^{33}{ }^{34}$ One arm-elevation-year was defined as working with elevated $\operatorname{arm}(\mathrm{s})$ $>90^{\circ}$ for $0.5 \mathrm{~h} /$ day for 1 year. One repetition-year was defined as performing moderately repetitive work for $4 \mathrm{~h} /$ day for 1 year or highly repetitive work for $1 \mathrm{~h} /$ day for 1 year. One force-year was defined as working with a force score of 2 for 1 year. One $\mathrm{HAV}$-year was defined as working with a hand-held vibrating tool with low acceleration for $1 \mathrm{~h}$ /day for 1 year, or working with a hand-held vibrating tool with moderate acceleration for $0.5 \mathrm{~h} /$ day for 1 year. No job group was rated in the highest acceleration group. We also constructed a joint shoulder load variable, which represented forceful work, upper arm elevation $>90^{\circ}$ and repetitive shoulder movements, either individually or in different combinations. ${ }^{18}$ Shoulder load was scored 0 (low exposure), 1 (medium exposure) or 2 (high exposure), and one shoulder-load-year was defined as having a shoulder load score of 1 for 1 year. To exemplify, a person who had a full-time job with elevated arms for $0.5 \mathrm{~h} /$ day for 2 years and a $27 \mathrm{~h} /$ week job with elevated arms for $1 \mathrm{~h} /$ day for 8 years would accrue $((1 \times 0.5 \mathrm{~h} /$ day $\times 2$ years $) / 0.5 \mathrm{~h} /$ day $)+((0.5 \times 1 \mathrm{~h} /$ day $\times 8$ years $) / 0.5$ $\mathrm{h} /$ day) $=10$ arm-elevation-years.

\section{Covariates}

We included sex, age, calendar year at start of follow-up, and region of residence (based on zip codes) as covariates. Region of residence was included to represent regional variations in surgery rates. From Statistics Denmark, we obtained year-by-year information on socioeconomic status (SES). For each person, we reclassified SES into five categories, ${ }^{33} 34$ and selected the most frequently used category from 1993 to end of follow-up. A priori, we decided only to include SES in supplementary analyses of risk in order to avoid overadjustment of our main results due to expected correlations with occupational biomechanical exposures. ${ }^{18}$

\section{Statistical analyses}

We used a logistic regression technique equivalent to discrete survival analysis, where number of follow-up intervals (of 1 year each) was included to account for differences in follow-up time. The resulting OR can be interpreted as a HR. ${ }^{35}$ We applied models with time-varying exposures using a 1-year lag time. Follow-up time was calculated from 1 January 2003 for persons with more than 5 years of full-time employment (or the equivalent, eg, 10 years of half-time employment) since 1 January 1993. Persons with less than 5 years of full-time employment by 1 January 2003 entered follow-up the year after they reached 5 years of full-time employment. Follow-up continued until surgery for SIS, censoring due to surgery for any shoulder disorder, ${ }^{36}$ the person's 70th birthday, death, disappearance or emigration (including change of address to Greenland), or 31 December 2008, whichever came first. In the adjusted analyses (adjusted OR, $\mathrm{OR}_{\mathrm{adj}}$ ), we included age (categorical, five categories) as a time varying variable, region of residence (categorical, five categories), calendar year at start of follow-up and sex. The analyses were supplemented by test for trend using exposure category as a continuous variable. Two-by-two correlation analyses were performed for all occupational exposures, and we controlled for SES in supplementary analyses. To compare the exposure-response relationships for men and women, the analyses were repeated for men and women separately. We used likelihood-ratio test to examine interactions (departure from multiplicativity) between sex and occupational exposures.

$$
\begin{aligned}
& \text { All persons born in Denmark, excluding Greenland, from } 1 \text { January } 1933 \text { to } 31 \text { December } 1977 \\
& N=3,384,199
\end{aligned}
$$

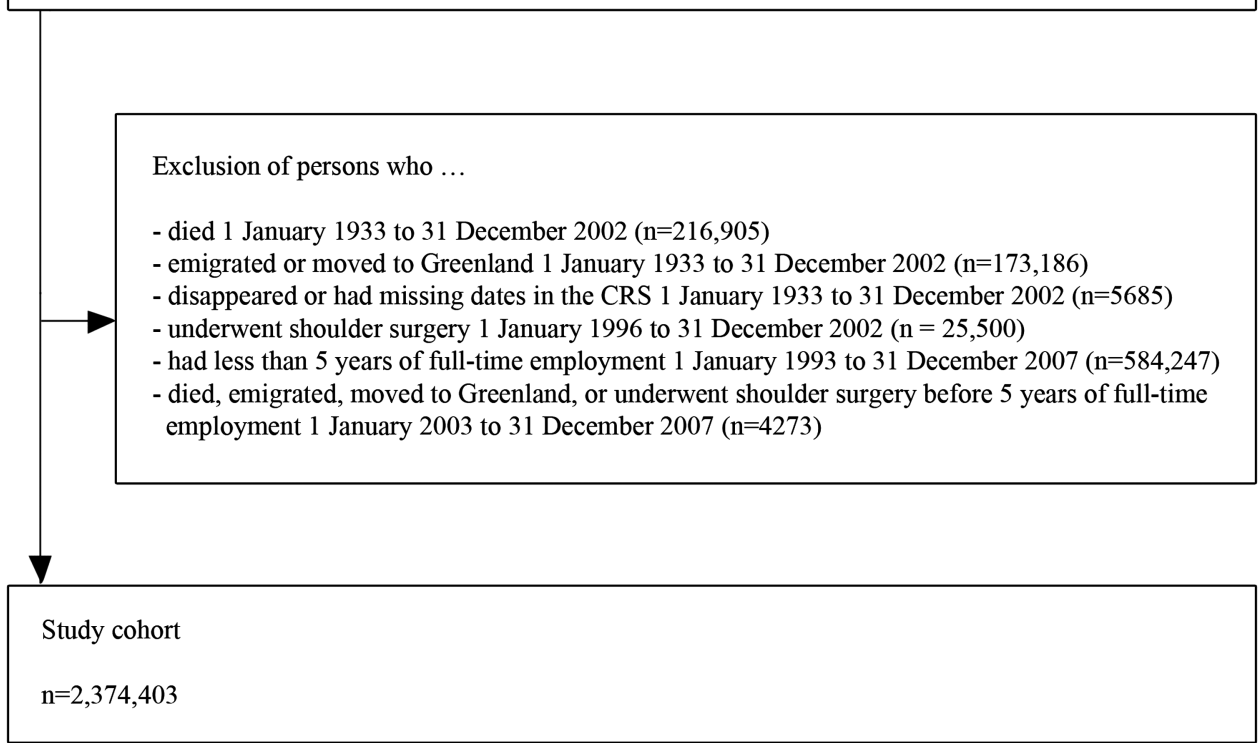

CRS $=$ Civil Registration System .

Figure 1 Flow chart from national birth cohort to study cohort. CRS, Civil Registration System. 
Any potential for prevention was evaluated by calculating the excess number of cases above the expected number among the exposed. This was carried out by multiplying the excess fraction $\left(\left(\mathrm{OR}_{\mathrm{adj}}-1\right) / \mathrm{OR}_{\mathrm{adj}}\right)$ for each exposure category of shoulder load with the number of cases within the exposure category, then summing up the excess numbers and dividing the sum by the total number of operations for SIS, and lastly converting to per cent. $^{37}$ The excess fraction within the general working population was also calculated separately for men and women.

To evaluate the time window of relevant exposure to upper arm elevation $>90^{\circ}$, we conducted a series of analyses where we focused on the most recent 2-year, 4-year, 6-year and 8-year time windows in addition to the originally selected 10 -year time window, still with a 1-year lag time. ${ }^{38-40}$ We used logistic regression adjusting for the covariates aforementioned and for exposure accumulated in the initial part of the original 10-year time window.

All analyses were performed on Statistics Denmark's research platform using STATA V.12.1 (Stata Corp, College Station, Texas, USA).

\section{RESULTS}

Figure 1 displays the establishment of the study cohort. The cohort comprised 2374403 persons, 1216772 men and 1157631 women. The most frequent D-ISCO 88 codes with high shoulder load were carpenters, mechanics and electricians among men, and machine operators and assemblers, slaughterhouse and fish processing workers, painters and laundry workers among women. Valid D-ISCO 88 codes were available for $82 \%$ of all observations (years of employment) from 1993 to 2007 .

The total follow-up time was 13332922 person-years, 6843877 for men and 6489045 for women, with a mean of 5.6 years per person for both men and women. During follow-up, 14118 first-time events of surgery for SIS occurred, corresponding to an incidence rate of 10.6/10 000 person-years (95\% CI 10.4-10.8), 10.7 (95\% CI 10.4 to 10.9) among men and 10.5 (95\% CI 10.3 to 10.8$)$ among women.

Table 1 shows characteristics of the person-years of follow-up for men and women. For all exposures, a higher percentage of men than women were in the highest exposure categories. Correlations between the occupational exposures ranged from 0.6 to 0.8 , and in sex-specific analyses from 0.6 to 0.8 among men and from 0.3 to 0.8 among women.

Table 2 shows crude and OR adj of surgery for SIS in relation to cumulative occupational shoulder exposures for the whole study population. Exposure-response relationships were observed for arm-elevation-years, repetition-years, force-years and shoulder-load-years with a maximum $\mathrm{OR}_{\mathrm{adj}}$ of around 2. An exposure-response relationship was also seen for $\mathrm{HAV}$-years with a maximum $\mathrm{OR}_{\text {adj }}$ of 1.5 . The ORs for female sex varied between 1.1 and 1.2 depending on exposure variable (all $\mathrm{p}$ values $<10^{-3}$ ). When controlling for SES, the $\mathrm{OR}_{\mathrm{adj}}$ decreased for all occupational exposures, but the overall pattern of associations did not change-for example, for arm-elevation-years, inclusion of SES reduced the $\mathrm{OR}_{\text {adj }}$ from 2.1 (95\% CI 2.0 to 2.2 ) to 1.8 (95\% CI 1.7 to 1.9 ). According to the excess fraction estimated based on shoulder load, 3346 (24\%) out of 14118 first-time events of surgery for SIS would in theory be preventable, 29\% among men and 17\% among women.

Figure 2 shows sex-specific $\mathrm{OR}_{\text {adj }}$ for surgery for SIS in relation to mean exposure level within categories of cumulative exposures. The exposure-response curves showed no differences
Table 1 Characteristics of 13332922 person-years of follow-up for men and women

\begin{tabular}{|c|c|c|}
\hline & Men & Women \\
\hline Person-years of follow-up & 51.3 & 48.7 \\
\hline \multicolumn{3}{|l|}{ Age category (years) } \\
\hline$\leq 35$ & 17.8 & 17.2 \\
\hline$>35-45$ & 28.7 & 29.7 \\
\hline$>45-55$ & 25.3 & 26.7 \\
\hline$>55-65$ & 22.8 & 22.3 \\
\hline$>65-70$ & 5.4 & 4.1 \\
\hline \multicolumn{3}{|l|}{ Socioeconomic status } \\
\hline Self-employed & 3.1 & 1.2 \\
\hline Top managers and employees at upper level & 18.8 & 13.4 \\
\hline Employees at intermediate level & 56.8 & 66.8 \\
\hline Employees at basic level & 14.4 & 9.6 \\
\hline Persons outside the labour market & 6.9 & 9.0 \\
\hline \multicolumn{3}{|l|}{ Arm-elevation-years } \\
\hline 0 & 25.2 & 39.2 \\
\hline$>0-2$ & 20.1 & 29.8 \\
\hline$>2-5$ & 13.7 & 16.6 \\
\hline$>5-10$ & 15.4 & 8.6 \\
\hline$>10-56$ & 25.6 & 5.8 \\
\hline \multicolumn{3}{|l|}{ Repetition-years } \\
\hline 0 & 39.7 & 62.3 \\
\hline$>0-1$ & 16.1 & 15.5 \\
\hline$>1-2$ & 11.9 & 5.2 \\
\hline$>2-10$ & 16.5 & 10.6 \\
\hline$>10-68$ & 15.8 & 6.4 \\
\hline \multicolumn{3}{|l|}{ Force-years } \\
\hline$<5$ & 20.2 & 33.4 \\
\hline 5 & 15.5 & 20.1 \\
\hline$>5-7.5$ & 23.9 & 29.2 \\
\hline$>7.5-10$ & 16.9 & 14.5 \\
\hline$>10-20$ & 23.5 & 2.8 \\
\hline \multicolumn{3}{|l|}{ HAV-years } \\
\hline 0 & 47.0 & 78.1 \\
\hline$>0-5$ & 32.5 & 20.3 \\
\hline$>5-58$ & 20.5 & 1.6 \\
\hline \multicolumn{3}{|l|}{ Shoulder-load-years } \\
\hline 0 & 28.7 & 27.1 \\
\hline$>0-5$ & 13.6 & 25.9 \\
\hline$>5-10$ & 16.3 & 29.0 \\
\hline$>10-15$ & 13.0 & 10.6 \\
\hline$>15-20$ & 28.4 & 7.4 \\
\hline
\end{tabular}

between men and women. This was corroborated by interaction analyses, which yielded $\mathrm{p}$ values ranging from 0.06 to 0.36 , apart from a $\mathrm{p}$ value of 0.02 for force-years.

When the exposure time window was prolonged from $2,4,6$, 8 and up to 10 years back in time, the $\mathrm{OR}_{\text {adj }}$ increased from 1.0 (95\% CI 0.8 to 1.3 ) to 1.6 (95\% CI 1.4 to 1.8$), 1.7$ (95\% CI 1.5 to 1.8 ), and 1.9 (95\% CI 1.7 to 2.0 ) to 2.1 (95\% CI 2.0 to 2.2) for the highest category of arm-elevation-years (ie, $>10$ ).

\section{DISCUSSION}

In this nationwide cohort study, we found positive exposureresponse relationships between cumulative exposure to work with upper arm elevation $>90^{\circ}$, repetitive shoulder movements, forceful shoulder exertions, and HAVs and surgery for SIS. 
Table $2 \mathrm{OR}^{*}$ of first-time surgery for SIS in relation to occupational biomechanical exposures

\begin{tabular}{|c|c|c|c|c|c|}
\hline Exposure & Surgery for SIS (n) & $\mathrm{OR}_{\text {crude }}$ & $95 \% \mathrm{Cl}$ & $\mathrm{OR}_{\mathrm{adj}}{ }^{\dagger}$ & $95 \% \mathrm{Cl}$ \\
\hline \multicolumn{6}{|c|}{ Arm-elevation-years } \\
\hline 0 & 3294 & 1.0 & - & 1.0 & - \\
\hline$>0-2$ & 3359 & 1.3 & 1.3 to 1.4 & 1.4 & 1.4 to 1.5 \\
\hline$>2-5$ & 2197 & 1.4 & 1.3 to 1.5 & 1.5 & 1.5 to 1.6 \\
\hline$>5-10$ & 2147 & 1.7 & 1.6 to 1.8 & 1.8 & 1.7 to 1.9 \\
\hline \multirow[t]{2}{*}{$>10-56$} & 3121 & 1.9 & 1.8 to 2.0 & 2.1 & 2.0 to 2.2 \\
\hline & & $p$ for trend $<10^{-3}$ & & $p$ for trend $<10^{-3}$ & \\
\hline \multicolumn{6}{|c|}{ Repetition-years } \\
\hline 0 & 6001 & 1.0 & - & 1.0 & - \\
\hline$>0-1$ & 1872 & 1.0 & 1.0 to 1.1 & 1.2 & 1.1 to 1.3 \\
\hline$>1-2$ & 1423 & 1.4 & 1.3 to 1.5 & 1.5 & 1.5 to 1.6 \\
\hline$>2-10$ & 2357 & 1.5 & 1.4 to 1.5 & 1.6 & 1.5 to 1.6 \\
\hline \multirow[t]{2}{*}{$>10-68$} & 2465 & 1.9 & 1.8 to 2.0 & 1.9 & 1.8 to 2.0 \\
\hline & & $p$ for trend $<10^{-3}$ & & $p$ for trend $<10^{-3}$ & \\
\hline \multicolumn{6}{|l|}{ Force-years } \\
\hline$<5$ & 2982 & 1.0 & - & 1.0 & - \\
\hline 5 & 1643 & 0.8 & 0.8 to 0.9 & 0.7 & 0.6 to 0.7 \\
\hline$>5-7.5$ & 3770 & 1.3 & 1.2 to 1.3 & 1.2 & 1.1 to 1.2 \\
\hline$>7.5-10$ & 2933 & 1.7 & 1.6 to 1.8 & 1.5 & 1.4 to 1.6 \\
\hline \multirow[t]{2}{*}{$>10-20$} & 2790 & 1.9 & 1.8 to 2.0 & 1.7 & 1.6 to 1.8 \\
\hline & & $p$ for trend $<10^{-3}$ & & $p$ for trend $<10^{-3}$ & \\
\hline \multicolumn{6}{|l|}{ HAV-years } \\
\hline 0 & 8064 & 1.0 & - & 1.0 & - \\
\hline$>0-5$ & 3937 & 1.1 & 1.0 to 1.2 & 1.3 & 1.2 to 1.3 \\
\hline \multirow[t]{2}{*}{$>5-58$} & 2117 & 1.5 & 1.4 to 1.5 & 1.5 & 1.5 to 1.6 \\
\hline & & $p$ for trend $<10^{-3}$ & & $\mathrm{p}$ for trend $<10^{-3}$ & \\
\hline \multicolumn{6}{|c|}{ Shoulder-load-years } \\
\hline 0 & 5893 & 1.0 & - & 1.0 & - \\
\hline$>0-5$ & 1794 & 1.2 & 1.2 to 1.3 & 1.4 & 1.3 to 1.5 \\
\hline$>5-10$ & 3745 & 1.7 & 1.6 to 1.8 & 1.7 & 1.6 to 1.7 \\
\hline$>10-15$ & 920 & 1.7 & 1.6 to 1.8 & 1.8 & 1.7 to 2.0 \\
\hline \multirow[t]{2}{*}{$>15-20$} & 1766 & 1.9 & 1.8 to 2.0 & 2.0 & 1.9 to 2.1 \\
\hline & & $p$ for trend $<10^{-3}$ & & $\mathrm{p}$ for trend $<10^{-3}$ & \\
\hline
\end{tabular}

${ }^{*}$ The OR can be interpreted as a $\mathrm{HR}^{35}$

†Adjusted for time varying age (five age categories), sex, region of residence (five regions) and calendar year at start of follow-up. We did not mutually adjust for other exposure variables due to expected colinearity. ${ }^{18}$

HAV, hand-arm-vibration; SIS, subacromial impingement syndrome.

High exposures to the three first-mentioned exposures carried an almost doubled risk, while the last-mentioned exposure carried an increase in risk by a factor of 1.5. Exposure-response relationships were similar for men and women, when assessed using a relative risk scale. The risk of surgery for SIS increased gradually with the number of years contributing to the cumulative exposure estimates within a 10-year time window without levelling off. In the general working population, a substantial fraction of operations for SIS could be related to cumulative occupational shoulder exposures, especially among men.

The main strength of the study was that the cohort comprised the entire Danish working population, and that information was gathered through high-quality longitudinal registers with nearly complete follow-up. Furthermore, we estimated individual cumulative exposures without recall bias by linking registered D-ISCO 88 codes with an independent JEM, which has shown high predictive validity in a recent study of surgery for SIS. ${ }^{18}$ The experts did not have information on the distribution of surgery for SIS across occupational titles, but from their previous research, they did have information on the prevalence of clinically diagnosed SIS for a few of the occupational titles represented in the JEM (eg, slaughterhouse workers and house painters). However, in these cases, they were able to base their ratings on detailed exposure information obtained by observation $^{13}$ and technical measurements. ${ }^{15}$ Therefore, we do not think that the experts' ratings were biased by their knowledge of the research hypothesis. A general limitation when using JEMs is the inherent misclassification of exposures at the individual level to the extent that individual exposures differ within job groups. However, based on theories of Berkson and classical errors, group-based exposure assessment usually results in little or no attenuation of the exposure-response relationships if study participants can be assigned to exposure groups that differ sufficiently with respect to their mean exposures. ${ }^{41}$ Another limitation was that we had no information on potential confounders such as leisure time physical activity, body mass index and smoking. However, SES is associated with several lifestyle factors, and may be a useful surrogate for these potential confounders. $^{42} 43$ Adjusting for SES did not change the overall pattern of associations.

The results are in agreement with previous findings showing an association between occupational shoulder exposures and clinically diagnosed SIS ${ }^{213-15}$; in particular, our results contributed to the relatively sparse evidence of exposure to $\mathrm{HAVs}$ as a risk 
Figure 2 Adjusted odds ratios* for surgery for subacromial impingement syndrome in relation to mean exposures within categories of cumulative exposures for men and women. Adjusted for time varying age (five age categories), sex, region of residence (five regions) and calendar year at start of follow-up. HAV, handarm-vibration
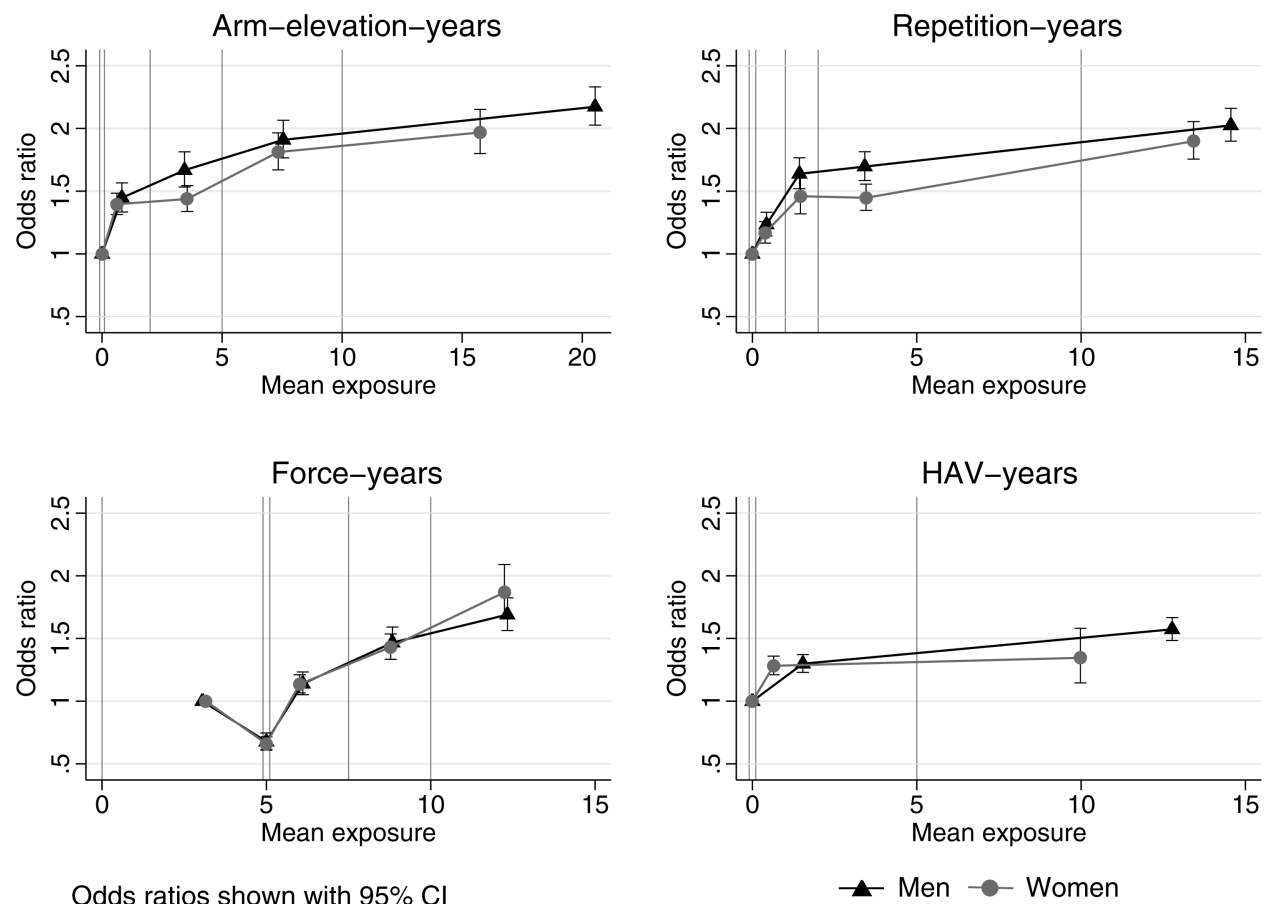

Odds ratios shown with $95 \% \mathrm{Cl}$ factor. $^{2} 1217$ Importantly, our study corroborated recent findings of an association between occupational shoulder exposures (assessed in terms of exposure intensities at baseline) and SIS leading to surgery. ${ }^{18}$ It is difficult to evaluate the importance of a single exposure since combined exposures are characteristic of occupational settings. ${ }^{13}$ Correspondingly, we were not able to mutually adjust the exposure variables due to high correlations-instead, we constructed the variable shoulder load to capture exposure profiles which implied an increased risk of surgery for SIS.

We may have failed to detect an increased vulnerability among women if we systematically overestimated occupational exposures for women or underestimated occupational exposures for men. ${ }^{44}$ This seems unlikely, but we are currently validating the experts' ratings against technical measurements among men and women. Although our analyses revealed similar ORs for men and women with equal cumulative exposure estimates, incidence rate differences (as opposed to ORs or relative risks) between exposed and unexposed women would be higher than incidence rate differences between exposed and unexposed men, due to the basic slightly increased risk of surgery for SIS among women (ORs between 1.1 and 1.2). ${ }^{45}$ Thus, a somewhat larger potential for prevention would exist for women than for men given the same initial level of exposure. We found that a substantial fraction of all operations for SIS in the general working population could be related to cumulative occupational shoulder exposures. This was particularly the case for men because high exposures were more common among men than among women.

Time windows of relevant exposures have been largely unaddressed with respect to SIS. We found a gradually increasing risk of surgery for SIS when the number of years contributing to the cumulative exposure estimates was increased from 2 to 10 . This indicated substantial long-term effects of occupational shoulder exposures on the risk of surgery for SIS. On the other hand, 2-4 years of accumulation of exposure effects was sufficient to increase the risk of surgery for SIS. To better understand the injury mechanisms at different time points in the process which leads from occupational shoulder exposures to SIS, it is important to disentangle effects of exposure duration and exposure intensity. ${ }^{46}$ Knowledge on the response of shoulder tissues to cumulative exposures might further increase our chance to identify exposure intensities, which do not lead to an increased risk of SIS, even with prolonged exposure duration.

Denmark has a public and free healthcare system, which minimises socioeconomic differences in access to surgery, and we think that our results may be generalisable to other countries with easy access to surgery for SIS. The observed exposureresponse relationships could be due to an increased risk of SIS or an increased risk of surgery given SIS, or both. In any case, we think that the findings of the present study suggest a need for preventive efforts. The risk could not be related to any generic exposure in particular. Therefore, we think that preventive efforts should aim to reduce overall shoulder exposures during working life.

In conclusion, our findings suggest that working with elevated arms, repetitive movements and forceful shoulder exertions carried an up to doubled risk of surgery for SIS. Exposure to HAVs carried an increase in risk by a factor of up to 1.5 . We found no difference in exposure-response relationships between men and women when assessed using a relative risk scale. The risk of surgery for SIS increased gradually, when the period of exposure assessment was extended. In the general working population, the results indicated that a substantial fraction of first-time operations for SIS can be related to cumulative occupational shoulder exposures and thus may be preventable.

Correction notice A sentence under 'Outcome' in 'Materials and Methods' and figure 2 have been modified since published Online First.

Acknowledgements The authors thank Jens Peder Haahr, Department of Occupational Medicine, Regional Hospital West Jutland-University Research Clinic, and Jane Frølund Thomsen, Department of Occupational and Environmental Medicine, Bispebjerg Hospital, University Hospital of Copenhagen, who provided expert ratings for the JEM. 
Contributors AD performed the statistical analyses and drafted the manuscript in collaboration with SWS and PF. All coauthors have assisted with interpretation of the findings and with revising the manuscript critically. All authors contributed to the conception and design of the study. The final version has been approved by all authors.

Funding This study was supported by the Danish Working Environment Research Fund (grant no. 32-2009-03), the Danish Graduate School Network in Public Health Science (GRASPH; grant no. 07-07-2009) and the Danish Rheumatism Association (grant no. A1024).

Competing interests None.

Provenance and peer review Not commissioned; externally peer reviewed.

\section{REFERENCES}

1 Huisstede BM, Miedema HS, Verhagen AP, et al. Multidisciplinary consensus on the terminology and classification of complaints of the arm, neck and/or shoulder. Occup Environ Med 2007;64:313-19.

2 Miranda $H$, Viikari-Juntura $E$, Heistaro $S$, et al. A population study on differences in the determinants of a specific shoulder disorder versus nonspecific shoulder pain without clinical findings. Am J Epidemiol 2005;161:847-55.

3 Roquelaure $Y, H a C$, Leclerc $A$, et al. Epidemiologic surveillance of upper-extremity musculoskeletal disorders in the working population. Arthritis Rheum 2006;55:765-78.

4 Frost $\mathrm{P}$, Andersen $\mathrm{JH}$. Shoulder impingement syndrome in relation to shoulder intensive work. Occup Environ Med 1999;56:494-8.

5 Kaergaard A, Andersen JH. Musculoskeletal disorders of the neck and shoulders in female sewing machine operators: prevalence, incidence, and prognosis. Occup Environ Med 2000;57:528-34.

6 Melchior $M$, Roquelaure $Y$, Evanoff $B$, et al. Why are manual workers at high risk of upper limb disorders? The role of physical work factors in a random sample of workers in France (the Pays de la Loire study). Occup Environ Med 2006;63:754-61

7 Nordander C, Ohlsson K, Balogh I, et al. Fish processing work: the impact of two sex dependent exposure profiles on musculoskeletal health. Occup Environ Med 1999:56:256-64.

8 Vitale MA, Arons RR, Hurwitz $S$, et al. The rising incidence of acromioplasty. J Bone Joint Surg Am 2010;92:1842-50.

9 Judge A, Murphy RJ, Maxwell R, et al. Temporal trends and geographical variation in the use of subacromial decompression and rotator cuff repair of the shoulder in England. Bone Joint J 2014:96-B:70-4.

10 Nordqvist A, Rahme H, Hovelius L, et al. Axelns sjukdomar [Shoulder diseases] Läkartidningen 2007:104:1492-6.

11 Svendsen SW, Frost P, Jensen LD. Time trends in surgery for non-traumatic shoulde disorders and postoperative risk of permanent work disability: a nationwide cohort study. Scand J Rheumatol 2012;41:59-65.

12 Bodin J, Ha C, Petit Le MA, et al. Risk factors for incidence of rotator cuff syndrome in a large working population. Scand J Work Environ Health 2012;38:436-46.

13 Frost $\mathrm{P}$, Bonde JP, Mikkelsen $\mathrm{S}$, et al. Risk of shoulder tendinitis in relation to shoulder loads in monotonous repetitive work. Am J Ind Med 2002:41:11-18.

14 Silverstein BA, Bao SS, Fan ZJ, et al. Rotator cuff syndrome: personal, work-related psychosocial and physical load factors. J Occup Environ Med 2008;50:1062-76.

15 Svendsen SW, Bonde JP, Mathiassen SE, et al. Work related shoulder disorders: quantitative exposure-response relations with reference to arm posture. Occup Environ Med 2004;61:844-53.

16 van Rijn RM, Huisstede BM, Koes BW, et al. Associations between work-related factors and specific disorders of the shoulder-a systematic literature review. Scand J Work Environ Health 2010;36:189-201.

17 Sutinen P, Toppila E, Starck J, et al. Hand-arm vibration syndrome with use of anti-vibration chain saws: 19-year follow-up study of forestry workers. Int Arch Occup Environ Health 2006;79:665-71.

18 Svendsen SW, Dalbøge A, Andersen JH, et al. Risk of surgery for subacromia impingement syndrome in relation to neck-shoulder complaints and occupational biomechanical exposures: a longitudinal study. Scand J Work Environ Health 2013;39:568-77
19 Andersen JH, Gaardboe 0. Musculoskeletal disorders of the neck and upper limb among sewing machine operators: a clinical investigation. Am J Ind Med 1993;24:689-700.

20 Werner RA, Franzblau A, Gell N, et al. A longitudinal study of industrial and clerical workers: predictors of upper extremity tendonitis. J Occup Rehabil 2005;15:37-46.

21 Miranda H, Punnett L, Viikari-Juntura E, et al. Physical work and chronic shoulder disorder. Results of a prospective population-based study. Ann Rheum Dis 2008;67:218-23

22 Armstrong TJ, Buckle P, Fine LJ, et al. A conceptual model for work-related neck and upper-limb musculoskeletal disorders. Scand J Work Environ Health 1993:19:73-84.

23 Wells R, Van ED, Hagg G. Mechanical exposure concepts using force as the agent Scand J Work Environ Health 2004:30:179-90.

24 Allander E. Prevalence, incidence, and remission rates of some common rheumatic diseases or syndromes. Scand J Rheumatol 1974:3:145-53.

25 Silverstein B, Fan ZJ, Smith CK, et al. Gender adjustment or stratification in discerning upper extremity musculoskeletal disorder risk? Scand J Work Environ Health 2009:35:113-26.

26 Hooftman WE, van der Beek AJ, Bongers PM, et al. Is there a gender difference in the effect of work-related physical and psychosocial risk factors on musculoskeletal symptoms and related sickness absence? Scand J Work Environ Health 2009:35:85-95.

27 Messing K, Silverstein BA. Gender and occupational health. Scand J Work Environ Health 2009:35:81-3.

28 Pedersen CB. The Danish Civil Registration System. Scand J Public Health 2011;39:22-5.

29 Hansen J, Lassen CF. The Supplementary Pension Fund Register. Scand J Public Health 2011;39:99-102.

30 Petersson F, Baadsgaard M, Thygesen LC. Danish registers on personal labour market affiliation. Scand J Public Health 2011;39:95-8.

31 Lynge E, Sandegaard JL, Rebolj M. The Danish National Patient Register. Scand J Public Health 2011;39:30-3.

32 Moore JS, Garg A. The strain index: a proposed method to analyze jobs for risk of distal upper extremity disorders. Am Ind Hyg Assoc J 1995;56:443-58

33 Vad MV, Frost $\mathrm{P}$, Bay-Nielsen $\mathrm{M}$, et al. Impact of occupational mechanical exposures on risk of lateral and medial inguinal hernia requiring surgical repair. Occup Environ Med 2012;69:802-9.

34 Rubak TS, Svendsen SW, Søballe K, et al. Risk and rate advancement periods of total hip replacement due to primary osteoarthritis in relation to cumulative physical workload. Scand J Work Environ Health 2013:39:486-94.

35 Richardson DB. Discrete time hazards models for occupational and environmental cohort analyses. Occup Environ Med 2010:67:67-71.

36 Andersen PK, Geskus RB, de Witte T, et al. Competing risks in epidemiology: possibilities and pitfalls. Int J Epidemiol 2012:41:861-70.

37 Greenland S, Robins JM. Conceptual problems in the definition and interpretation of attributable fractions. Am J Epidemiol 1988;128:1185-97.

38 Rothman KJ. Induction and latent periods. Am J Epidemiol 1981;114:253-9.

39 Checkoway H, Pearce N, Hickey JL, et al. Latency analysis in occupational epidemiology. Arch Environ Health 1990;45:95-100.

40 Rothman KJ, Greenland S, Lash TL. Modern epidemiology. In: wahrendorf J, ed 3rd edn. Lippincott Williams \& Wilkins. 2008:288.

41 Armstrong BG. Effect of measurement error on epidemiological studies of environmental and occupational exposures. Occup Environ Med 1998;55:651-6.

42 Pearce N, Checkoway H, Kriebel D. Bias in occupational epidemiology studies. Occup Environ Med 2007:64:562-8.

43 Pukkala E. Cancer risk by social class and occupation: a survey of 109,000 cance cases among Finns of working age. In: Contributions to epidemiology and biostatistics. vol 7. 1995. Basel: Karger, 288

44 Messing K, Dumais L, Courville J, et al. Evaluation of exposure data from men and women with the same job title. J Occup Med 1994:36:913-17.

45 Rothman KJ, Greenland S, Walker AM. Concepts of interaction. Am J Epidemio 1980;112:467-70.

46 Lubin JH, Caporaso NE. Cigarette smoking and lung cancer: modeling total exposure and intensity. Cancer Epidemiol Biomarkers Prev 2006;15:517-23. 